\title{
Reverse Breech Extraction Versus Dis-Impaction of the Head During Cesarean Section for Obstructed Labor
}

\author{
Ashraf Mohamed Safwat Ibrahim* \\ MD in Obstetrics and Gynecology, Consultant of Obstetrics and Gynecology and IVF. Cairo, Egypt
}

Submission: June 08, 2020 ; Published: June 17, 2020

*Corresponding author: Ashraf Mohamed Safwat Ibrahim, MD in Obstetrics and Gynecology, Consultant of Obstetrics and Gynecology and IVF. Cairo, Egypt

\begin{abstract}
Abstarct
Obstructed labor is most frequently due to mechanical causes: a mismatch between fetal size and the mother's pelvis (feto-pelvic disproportion) or, more precisely, the size of the fetal presenting part and the mother's pelvis. Malposition of the fetal head as in occipito-posterior and deep transverse arrest positions may also cause obstruction. Malpresentations, in particular a brow presentation or a shoulder presentation in a transverse or oblique lie, are further causes of obstruction. In rare cases, pathological enlargement of fetal head (as in hydrocephalus), locked twins or pelvic tumors can cause obstruction. Failure of the cervix to dilate during labor despite adequate uterine contractions is rarely secondary to cervical scarring causing stenosis Two distinct techniques have been suggested to overcome the difficulty of delivering the fetus and reduce maternal and fetal risks during CS for obstruction late in second stage of labor OF breech presentation : the 'standard approach' of pushing the fetal head up through the vagina or the 'reverse breech extraction approach 'The objective of this study was to assess the effectiveness and safety of the reverse breech extraction, and compare it with the standard approach of pushing up through the vagina, in delivering the deeply impacted fetal head during emergency CS for prolonged obstruction in advanced second stage of labor. This study shows that the reverse breech extraction technique for delivery of a deeply impacted fetal head in second-stage caesarean section carries a significantly lower risk of extension of the uterine incision compared with the push method. It is also associated with a lower risk of infection a lower operative time, and less operative blood loss; however, there is no difference in blood transfusion rate and neonatal outcome. Limited evidence from three small observational studies suggests that the reverse breech extraction method is associated with a lower risk of uterine extension and a lower risk of blood transfusion, with no difference in neonatal outcome. There is an urgent need to develop trainees' skills on the use of several of these methods to deliver the impacted fetal head, and thus reduce complications associated with full-dilation caesarean section.
\end{abstract}

Keywords: Feto-Pelvic Disproportion; Hydrocephalus; Pelvic Tumors; Cervix; Fetal Head; Breech Extraction; Blood Transfusion

Abbreviations: CPD: Cephalopelvic Disproportion; CS: Caesarean Section; IQR: Inter Quartile Range

\section{Introduction}

Obstructed labor is defined as no progress in labor as shown by the failure of cervix to dilate or failure of fetal presenting part to descend through the birth canal or both despite adequate uterine contractions [1].

Although rare in developed countries, it is still a common obstetric problem in developing countries [2]. Globally, obstructed labor is a major cause of both maternal and neonatal morbidity and mortality [2-10].

Obstructed labor is most frequently due to mechanical causes: a mismatch between fetal size and the mother's pelvis (feto-pelvic disproportion) or, more precisely, the size of the fetal presenting part and the mother's pelvis [11]. Malposition of the fetal head as in occipito-posterior and deep transverse arrest positions may also cause obstruction.

Malpresentations, a brow presentation or a shoulder presentation in a transverse or oblique lie, are further causes of obstruction. In rare cases, pathological enlargement of fetal head (as in hydrocephalus), locked twins or pelvic tumors can cause obstruction. Failure of the cervix to dilate during labor despite adequate uterine contractions is rarely secondary to cervical scarring causing stenosis. This could be the result of cervical 
amputation or cone biopsy. Different causes of obstructed labour may co-exist. However, the common causes of this condition are cephalopelvic disproportion (CPD), fetal malpositions and malpresentations $[1,12]$.

In cases of obstruction, late in second stage of labor, the dilemma which obstetricians frequently encounter is how to keep the maternal and neonatal morbidity, as well as mortality, to a minimum when given a choice between difficult instrumental delivery and caesarean section (CS). In these circumstances, instrumental delivery may fail, or cause fetal and maternal complications at the time when CS stands as a relatively safer option, and the proportion of second stage CS is, therefore, on the rise [13].

However, late in second stage of labor, emergency CS is not without risks as the fetal head is deeply impacted with limited space for trying to disengage it abdominally. This makes it difficult for the surgeon to safely deliver the fetal head, especially when the lower uterine segment is already edematous, thin and overstretched $[14,15]$. There is a high risk of inadvertent extension of uterine incision and injury to uterine vessels, ureters and urinary bladder with the resultant increased blood loss and prolonged operative time when more operative steps are performed [13].

Two distinct techniques have been suggested to overcome the difficulty of delivering the fetus and reduce maternal and fetal risks during CS for obstruction late in second stage of labor: the 'standard approach' of pushing the fetal head up through the vagina or the 'reverse breech extraction approach' $[8,13,16]$. The objective of this study was to assess the effectiveness and safety of the reverse breech extraction, and compare it with the standard approach of pushing up through the vagina, in delivering the deeply impacted fetal head during emergency CS for prolonged obstruction in advanced second stage of labor.

\section{Aim of Study}

Improve maternal and fetal outcome in obstructed labor.

\section{Methods and Materials}

This study was conducted from 20 January 2018 to 30 October 2019. This study is prospective study include (40) patient that have been submitted for emergency caesarian section with deeply engaged fetal head. All the patients had the following criteria singleton pregnancies 2nd stage of (1 hour). Fully dilated cervix of PG \& ( 2 hour) of MP without epidural analgesia So, if any patient fulfills criteria of study she already known and signed the consent in equine stage of labor All patient had a continuous fetal monitory during 2nd stage of labor with external monitory with reading CTG till delivery.

Eligible women were randomized in a proportion of 1:1 either to the "reverse breech extraction approach" group, were the baby was delivered by reverse breech extraction or the standard approach group where pushing the fetal head up through the vagina was carried out. All Women admitted to labor word were counseled, a clear explanation of procedures was given, and written informed consent was then obtained from all patients All patients take complete history, clinical examination All women were diagnosed as having abstracted labor that requires an abdominal delivery by CS.

\section{Inclusion Criteria}

Women with singleton, term (37-42 weeks) pregnancy, cephalic presentation, who were actively pushing with uterine contractions in the second stage of labor $1 \mathrm{~h}$ (multipara) or $2 \mathrm{~h}$ (primipara) with fetal caput head with obstructed Labor and not eligible for instrumental delivery or those with failed instrumental vaginal delivery and requiring abdominal delivery, were eligible and those who agreed to participate in the study were recruited.

\section{Exclusion Criteria}

Women with multiple pregnancy, preterm (37 weeks gestation), non-cephalic presentation or pervious uterine scar excludes, intrauterine fetal death, congenital fetal anomaly Preoperative preparations and anesthetic techniques were similar in all cases in both groups. The decision for the performance of the reverse breech extraction or to go on with push approach was taken in the operating by the operating surgeon; Group2 (study group) $(n=20)$ is < pull method > consists of all cases in which extraction of fetus was done by reverse breech extraction technique and Group1 (control) $(n=20)$ is $<$ push method $>$ in whom extraction of fetus was done by push method and extracted as vertex. Selective complications like extension of the incision, injury to the surrounding structures, excessive bleeding, need for blood transfusion and the fetal outcome were observed and compared.

Reverse breech extraction Technique $[8,16]$ The main operating hand of obstetric surgeon was inserted upward inside the uterine cavity to find and grasp a baby`s foot and deliver it along with ipsilateral leg through the uterine incision, this in turn brought the other leg into the operative field, the surgeon then grasped both feet and proceeded in manner similar to that practiced in vaginal breech extraction.

Push method [8,9] After opening the uterus, the patient is positioned in the supine position with the knees flexed and the lower legs abducted by two assistants. One of the assistants under sterile condition introduces his gloved finger into the vagina and then pushes the head up disimpacting it. The surgeon then introduces his hand into the uterus between the fetal head and the uterine wall, maneuvering his hand downwards to get beneath the fetal head as the assistant disimpacts the fetal head from below. The patient's legs are then returned to normal position. The Surgeon then delivers the fetal head and the rest of the fetus as it is performed in routine caesarean section After fetal delivery and 
clamping of the umbilical cord, each woman received antibiotic prophylaxis (1g of intravenous [IV]cefazolin). The placenta was then removed via gentle traction and exterior massage of the uterus; it was removed manually only if retained for more than 5 minutes.

The uterine cavity was closed in (2) layers with vicryl NO. zero sutures. Subcutaneous tissue was irrigated thoroughly with sterile saline before closure. After skin closure, the incision was dressed in a sterile bandage, which was removed on the second postoperative day. Per hospital policy, patients received $1 \mathrm{~g}$ of IV cefazolin 8-hourly (the first dose was administered intraoperatively after delivery). Patients without complications were discharged on the third or fourth postoperative day Distribution of women to either group was made randomly based on 1:1 ratio. written consent was obtained from each participant, and the confidentiality was ensured. The demographic and clinical data included age, parity, gestational age, antenatal care visits, pregnancy complications, and the course and complications during previous delivery. Also, we observed the operation time and intraoperative complications such as uterine rupture, and extension of the incision tear. Blood loss, postpartum hemorrhage fetal birth weight, gender, Apgar score and neonatal morbidity were noted. Blood hemoglobin Post-operative care was similar in both groups if needed woman were given anti-thromboembolic measures, according to hospital protocol. Hemoglobin checked 24 h postoperatively. Factors which determined the need for blood transfusion included hemodynamic status (heart rate, blood pressure, and urine output) as well as nature, amount and rate of blood loss. Primary outcome measure was to assess effectiveness of the reversed breech extraction approach in caesarean section for obstructed labor and compare it with the standard approach of pushing the fetal up through the vagina. Secondary outcome measures included extension of uterine incision, Intraoperative and postoperative blood loss, blood transfusion, total operative time (from skin incision to skin closure), extent of fall in maternal hemoglobin postoperatively, fetal birth weight, Apgar score 7 at 1 and 5 minutes, admission to special care baby unit (SCBU), other maternal and fetal morbidity and mortality and finally length of hospital stay, fetal injury during cs.

\section{Data Management and Statistical Analysis}

Datawere collected, coded, revised and entered to the Statistical Package for Social Science (IBM SPSS) version 20. The data were presented as number and percentages for the qualitative data,

Table 1: Comparison between standard group and reverse breech extraction as regards demographic data.

\begin{tabular}{|c|c|c|c|c|c|c|c|c|c|c|}
\hline & \multicolumn{4}{|c|}{$\begin{array}{l}\text { Standard Group } \\
(\mathrm{N} 0 .=20)\end{array}$} & \multicolumn{4}{|c|}{ Reverse Breech Extraction } & \multicolumn{2}{|c|}{$\begin{array}{c}\text { Independent } \\
\text { T-Test/Chi Square } \\
\text { Test }\end{array}$} \\
\hline & Mean & SD & Min & Max & Mean & SD & Min & $\operatorname{Max}$ & $t / X^{2}$ & P-value \\
\hline \multicolumn{11}{|l|}{ Fetal sex } \\
\hline Female & \multicolumn{2}{|c|}{10} & \multicolumn{2}{|c|}{$50.00 \%$} & \multicolumn{2}{|c|}{10} & \multicolumn{2}{|c|}{$50.00 \%$} & \multirow{2}{*}{0} & \multirow{2}{*}{1} \\
\hline Male & \multicolumn{2}{|c|}{10} & \multicolumn{2}{|c|}{$50.00 \%$} & & & \multicolumn{2}{|c|}{$50.00 \%$} & & \\
\hline
\end{tabular}

mean, standard deviations and ranges for the quantitative data with parametric distribution and median with inter quartile range (IQR) for the quantitative data with non-parametric distribution. Chi-square test was used in the comparison between two groups with qualitative data and Fisher exact test was used instead of the Chi-square test when the expected count in any cell found less than 5. Independent t-test was used in the comparison between two groups with quantitative data and parametric distribution and Mann-Whitney test was used in the comparison between two groups with quantitative data and non-parametric distribution The confidence interval was set to $95 \%$ and the margin of error accepted was set to $5 \%$. So, the p-value was considered significant as the following:
a) P > 0.05: Nonsignificant (NS)
b) $\quad \mathrm{P}<0.05$ : Significant $(\mathrm{S})$
c) $\mathrm{P}<0.01$ : Highly significant (HS)

\section{Result}

AS shown in Table 1 that there was statistically significant increase in standard group in comparison to reverse breech extraction with gestational age and HB post operation but there was no statistically significant deference in sex, age and HB pre operation as regards both groups. there was statistically significant increase in standard group in comparison to reverse breech extraction with blood transfusion but there was no statistically significant deference in extension of uterine incision, uterine artery laceration, brood ligament hematoma, bladder injury, atonic PPH, need for hysterectomy, blood lose and operative time, total complication, no complication as regards both groups Table $2 \& 3$. there was statistically significant decrease in reverse breech extraction in comparison to standard group with mean frequent, mean length stay in hospital and there was statistically significant increase in standard group in wound infection and mean length stay in hospital but there was no statistically significant deference in postpartum hemorrhage, blood transfusion, pyrexia and wound infection as regards both groups Table 4. there was statistically significant decrease in reverse breech extraction in comparison to standard group with Apgar score at 1 and $5 \mathrm{~min}$ but that there was no statistically significant difference in birth weight, still birth, admission, fetal injury, fetal distress, meconium stained and death as regard both groups Table 5. there was no statistically significant difference in anti-natal care as regard both groups Table 6 . 


\section{Journal of Gynecology and Women's Health}

\begin{tabular}{|c|c|c|c|c|c|c|c|c|c|c|}
\hline Gestational age(wks) & 38.95 & 1.64 & 37 & 41 & 37.45 & 1.96 & 34 & 40 & 2.627 & 0.012 \\
\hline Mother age(yr) & 29.45 & 6.07 & 23 & 41 & 30.85 & 7.34 & 20 & 44 & -0.657 & 0.515 \\
\hline HB pre operation (g\%) & 10.7 & 1.56 & 8 & 13 & 11.2 & 1.15 & 9 & 13 & -1.153 & 0.256 \\
\hline HB post operation (g\%) & 9.9 & 1.07 & 8 & 10 & 11.45 & 0.82 & 10 & 13 & -5.126 & $<0.001$ \\
\hline \multicolumn{11}{|l|}{ Parity } \\
\hline Nill & \multicolumn{2}{|c|}{10} & \multicolumn{2}{|c|}{$50.00 \%$} & \multicolumn{2}{|c|}{10} & \multicolumn{2}{|c|}{$50.00 \%$} & & \\
\hline Once & \multicolumn{2}{|c|}{5} & \multicolumn{2}{|c|}{$25.00 \%$} & \multicolumn{2}{|c|}{4} & \multicolumn{2}{|c|}{$20.00 \%$} & & \\
\hline Twice & \multicolumn{2}{|c|}{4} & \multicolumn{2}{|c|}{$20.00 \%$} & \multicolumn{2}{|c|}{2} & \multicolumn{2}{|c|}{$10.00 \%$} & 5.778 & 0.216 \\
\hline Three time & \multicolumn{2}{|c|}{1} & \multicolumn{2}{|c|}{$5.00 \%$} & \multicolumn{2}{|c|}{0} & \multicolumn{2}{|c|}{$0.00 \%$} & & \\
\hline Four times & \multicolumn{2}{|c|}{0} & \multicolumn{2}{|c|}{$0.00 \%$} & \multicolumn{2}{|c|}{4} & \multicolumn{2}{|c|}{$20.00 \%$} & & \\
\hline
\end{tabular}

HB: Hemoglobin

Table 2: Comparison between standard group and reverse breech extraction as regards CPD and mal position.

\begin{tabular}{|c|c|c|c|c|c|c|}
\hline & \multicolumn{2}{|c|}{$\begin{array}{l}\text { Standard Group } \\
\text { (N0.=20) }\end{array}$} & \multicolumn{2}{|c|}{$\begin{array}{l}\text { Reverse Breech Extraction } \\
\text { (N0.=20) }\end{array}$} & \multicolumn{2}{|c|}{ Chi Square Test } \\
\hline & $\mathrm{PG}$ & MP & $\mathrm{PG}$ & MP & \multirow{3}{*}{$\mathrm{X}^{2}$} & \multirow{3}{*}{ P-value } \\
\hline & 10 & 10 & 10 & 10 & & \\
\hline & No.(\%) & No.(\%) & No.(\%) & No.(\%) & & \\
\hline CPD & $3(30 \%)$ & $4(40 \%)$ & $2(20 \%)$ & $7(70 \%)$ & \multirow{2}{*}{5.833} & \multirow{2}{*}{0.12} \\
\hline Mal position & $7(70 \%)$ & $6(60 \%)$ & $8(80 \%)$ & $3(30 \%)$ & & \\
\hline
\end{tabular}

CPD; cephalo-pelvic disproportion ,MP; multipara , PG; primigravida

Table 3: Comparison between standard group and reverse breech extraction as regards intra operative data.

\begin{tabular}{|c|c|c|c|c|c|c|}
\hline & \multicolumn{2}{|c|}{ Standard Group (NO.=20) } & \multicolumn{2}{|c|}{$\begin{array}{l}\text { Reverse Breech Extraction } \\
\text { (N0.=20) }\end{array}$} & \multicolumn{2}{|c|}{ Independent T-Test/Chi Square Test } \\
\hline & No. & $\%$ & No. & $\%$ & $\mathrm{t} / \mathrm{X} 2$ & P-value \\
\hline Extension of uterine incision & 5 & $25 \%$ & 2 & $10 \%$ & 1.558 & 0.211 \\
\hline Uterine artery laceration & 3 & $15 \%$ & 1 & $5 \%$ & 1.111 & 0.291 \\
\hline Brood ligament hematoma & 1 & $5 \%$ & 0 & $0 \%$ & 1.026 & 0.311 \\
\hline Bladder injury & 1 & $5 \%$ & 0 & $0 \%$ & 1.026 & 0.311 \\
\hline Atonic PPH & 5 & $25 \%$ & 2 & $10 \%$ & 1.558 & 0.211 \\
\hline Blood transfusion needed & 10 & $50 \%$ & 2 & $10 \%$ & 7.619 & 0.005 \\
\hline Need for hysterectomy & 1 & $5 \%$ & 0 & $0 \%$ & 1.026 & 0.311 \\
\hline Blood lose & 11 & $55 \%$ & 6 & $30 \%$ & 2.558 & 0.11 \\
\hline Total complication & 12 & $70 \%$ & 10 & $50 \%$ & 0.404 & 0.525 \\
\hline No complication & 8 & $30 \%$ & 10 & $50 \%$ & 0.404 & 0.525 \\
\hline \multicolumn{7}{|l|}{ Operative time } \\
\hline Mean \pm SD & 33 & 11.85 & 29.5 & 5.83 & \multirow{2}{*}{1.185} & \multirow{2}{*}{0.243} \\
\hline Range & 20 & 55 & 20 & 40 & & \\
\hline
\end{tabular}

CS: cesarean section

HB: Hemoglobin 


\section{Journal of Gynecology and Women's Health}

Table 4: Comparison between standard group and reverse breech extraction as regards post-operative data.

\begin{tabular}{|c|c|c|c|c|c|c|}
\hline & \multicolumn{2}{|c|}{ Standard Group $(\mathrm{N} 0 .=20)$} & \multicolumn{2}{|c|}{$\begin{array}{c}\text { Reverse Breech Extraction } \\
(\text { N0.=20) }\end{array}$} & \multicolumn{2}{|c|}{$\begin{array}{c}\text { Independent T-Test/Chi } \\
\text { Square Test }\end{array}$} \\
\hline & No. & $\%$ & No. & $\%$ & $t / X^{2}$ & P-value \\
\hline Post-partum hemorrhage & 7 & $35.00 \%$ & 4 & $20.00 \%$ & 1.129 & 0.288 \\
\hline Blood transfusion & 5 & $25.00 \%$ & 3 & $15.00 \%$ & 0.625 & 0.429 \\
\hline Pyrexia & 3 & $15.00 \%$ & 1 & $5.00 \%$ & 1.11 & 0.291 \\
\hline Wound infection & 10 & $50.00 \%$ & 2 & $10.00 \%$ & 7.619 & 0.005 \\
\hline \multicolumn{7}{|c|}{ Mean length stay in hospital (day) } \\
\hline Mean \pm SD & 5.4 & 2.09 & 3.95 & 1.61 & \multirow{2}{*}{2.463} & \multirow{2}{*}{0.018} \\
\hline Range & 3 & 10 & 2 & 7 & & \\
\hline
\end{tabular}

Table 5: Comparison between standard group and reverse breech extraction as regards neonatal outcome.

\begin{tabular}{|c|c|c|c|c|c|c|c|c|c|c|}
\hline & \multicolumn{4}{|c|}{$\begin{array}{l}\text { Standard Group } \\
\text { (N0.=20) }\end{array}$} & \multicolumn{4}{|c|}{$\begin{array}{l}\text { Reverse Breech Extraction } \\
(\text { N0.=20) }\end{array}$} & \multicolumn{2}{|c|}{$\begin{array}{l}\text { Independent T-Test/ } \\
\text { Mann-Whitney }\end{array}$} \\
\hline & Mean & SD & Min & Max & Mean & SD & Min & Max & $t / Z$ & P-value \\
\hline Birth weight & 3.27 & 0.57 & 2 & 4.1 & 3.21 & 0.63 & 2.5 & 4.5 & 0.317 & 0.753 \\
\hline Apgar score 1m (Median, IQR) & $5.5(4-8)$ & & 3 & 9 & $9(8-10)$ & & 7 & 10 & -4.74 & 0.001 \\
\hline $\begin{array}{c}\text { Apgar score at } 5 \text { m (Median, } \\
\text { IQR) }\end{array}$ & $9(8-10)$ & & 6 & 10 & $10(10-10)$ & & 9 & 10 & -3.474 & 0.003 \\
\hline & \multicolumn{4}{|c|}{$\begin{array}{l}\text { Standard Group } \\
(\mathrm{N} 0 .=20)\end{array}$} & \multicolumn{4}{|c|}{$\begin{array}{l}\text { Reverse Breech Extraction } \\
(\text { N0.=20) }\end{array}$} & $\begin{array}{l}\text { Chi Square } \\
\text { Test }\end{array}$ & \\
\hline Still birth & \multicolumn{2}{|l|}{ No. } & \multicolumn{2}{|c|}{$\%$} & \multicolumn{2}{|c|}{ No. } & \multicolumn{2}{|c|}{$\%$} & $\mathrm{X} 2$ & P-value \\
\hline Die & \multicolumn{2}{|l|}{1} & \multicolumn{2}{|c|}{$5.00 \%$} & \multicolumn{2}{|l|}{0} & \multicolumn{2}{|c|}{$0.00 \%$} & 2.105 & 0.147 \\
\hline Alive & \multicolumn{2}{|l|}{19} & \multicolumn{2}{|c|}{$95 \%$} & \multicolumn{2}{|c|}{20} & \multicolumn{2}{|c|}{$100.00 \%$} & & \\
\hline Admission SCBU & \multicolumn{2}{|l|}{5} & \multicolumn{2}{|c|}{$25 \%$} & \multicolumn{2}{|l|}{2} & \multicolumn{2}{|c|}{$10 \%$} & 1.558 & 0.211 \\
\hline Fetal injury & \multicolumn{2}{|l|}{0} & \multicolumn{2}{|c|}{$0 \%$} & \multicolumn{2}{|l|}{1} & \multicolumn{2}{|c|}{$5.00 \%$} & 1.026 & 0.311 \\
\hline Death & \multicolumn{2}{|l|}{1} & \multicolumn{2}{|c|}{$5.00 \%$} & \multicolumn{2}{|l|}{0} & \multicolumn{2}{|c|}{$0.00 \%$} & 1.026 & 0.311 \\
\hline Fetal distress & \multicolumn{2}{|l|}{5} & \multicolumn{2}{|c|}{$25 \%$} & \multicolumn{2}{|l|}{2} & \multicolumn{2}{|c|}{$10 \%$} & 1.558 & 0.211 \\
\hline Meconium stained & \multicolumn{2}{|l|}{8} & \multicolumn{2}{|c|}{$40 \%$} & \multicolumn{2}{|l|}{4} & \multicolumn{2}{|c|}{$20 \%$} & 1.905 & 0.167 \\
\hline
\end{tabular}

Table 6: Comparison between standard group and reverse breech extraction as regards anti natal care.

\begin{tabular}{|c|c|c|c|c|c|c|c|}
\hline \multicolumn{2}{|c|}{ No. } & \multicolumn{2}{|c|}{$\begin{array}{l}\text { Standard Group } \\
\quad(\mathrm{N} 0 .=20)\end{array}$} & \multicolumn{2}{|c|}{$\begin{array}{l}\text { Reverse Breech Extraction } \\
\text { (N0.=20) }\end{array}$} & \multicolumn{2}{|c|}{ Chi Square Test } \\
\hline & & $\%$ & No. & $\%$ & X2 & P-value & \\
\hline \multirow[t]{2}{*}{ Anti natal care } & Irregular & 7 & $35.00 \%$ & 10 & $50.00 \%$ & \multirow{2}{*}{0.921} & \multirow{2}{*}{0.337} \\
\hline & Regular & 13 & $65.00 \%$ & 10 & $50.00 \%$ & & \\
\hline
\end{tabular}

\section{Discussion}

After prolonged obstructed labor, the operator frequently encounters a fetal head deeply impacted in the mid pelvis accompanied by a greatly elongated and thinned lower uterine segment [17]. Delivery can be done by slipping of surgeon hand deeply into the lower uterine segment between the symphysis 
pubis and fetal head and gentle elevation of fetal head with the fingers and palm through the incision, accepting the probability of lower uterine segment tears [18]. It was speculated that pushing of a fetal head through a vagina might prevent extension of the uterine incision and tears at the lower segment by avoiding manipulation of surgeon's hand when attempting to disengage the impacted fetal head from the pelvis, but this technique was associated with higher rate of extension of uterine segment, bleeding, requirement of blood transfusion and higher incidence of postpartum hemorrhage, also a non-sterile nature of this technique is associated with high rate of ascending infection also it associated with increased period of hospitalization [19]. This study compared this method of delivery of impacted fetal head with other method which is extracting a fetus by reverse breech extraction (pull method).The study show that a( pull method) performed by opening the uterus high to reach into the upper segment for a fetal leg ,and by applying gentle traction on the leg until another leg appeared and associated with lower rate of maternal complications. Cesarean section in the second stage of labor are often associated with higher complications rate and morbidity $[19,20]$. Women with prolonged second stage of labor or obstructed labor are likely have a contaminated endometrial cavity because of prolonged rupture of membranes and repeated digital examination [21], almost all women with obstructed labor present with foul- smelling and thick amniotic fluid resulting from full-brown chorioamnionitis, and this might also have the case for the majority of patients included in the present analysis. Therefore, it the push method in itself were a strong predictor of wound infection because of

contamination of the operation field by assistant pushing from below, as suggested by previous authors [20,22]. In our study there was no difference between the two groups regarding the age where obstructed labor tend to occur more in women of $<25$ year old and $>40$ year and this agree with levy et al research [8]. Regarding the parity no significant difference between the two groups this in agreement with Levy et al [8], but in general obstructed labor tend to occur mostly in nullipara rather than multipara. The incidence of obstructed labor varies widely in different countries and units across the world. Such variation may due to number of factors including variations in definition of obstructed labor setting, availability of resources as well as to unexplained difference in opinion and practice.

Rate between $0.6 \%$ and $6 \%$ have been reported [3-12]. The main cause of obstructed labor in this study is CPD in reverse breech extraction groups (90\%) but in standard groups (70\%) this agree with other investigators $(5,12,72-74)$.There is a problem of malpractice of unskilled midwives in our community and a large number of these patients come in a state of obstructed labor, one of these cases who delivered by pushing method had a hysterectomy for uncontrolled bleeding.

Patient delivered by (pushing method) had significant difference in intra operative complications as extension to the lower uterine segment and cervix as compared to the (pulling method) ,this mostly due to manipulation to the thin elongated lower uterine segment, this in agreement with Levy et al. [10], Frass et al. [12], Chopra et al. [15], Fong et al. [23], Abdeldayem $\mathrm{HM}$, et al. [24]. In this study 5(25\%) vs 2(10\%), respectively with and difference between the two groups was statistically highly significant $(\mathrm{p}=0.211)$.

However. from our experience in many cases, the extension tear related to (push method) can be at least minimized when some preventive actions are taken at time of CS. Mobilization of the bladder off the cervix deeply downwards could likely protect the bladder from possible involvement when the extension tears do occur. Also, when the surgeon fingers can get beneath the presenting part, it is advisable to sustain the elevation of fetal head upwards until it brings the lower and flexed part of the vertex into the open incision.

The delivery of the head before this point may result in laceration.

Similarly, using excessive force to deliver the fetal head may result in extension of the uterine incision. It was noted in this series that the reverse breech extraction approach group was associated with statistically significant lower mean blood loss intra-operatively than standard approach group $(11(50 \% \mathrm{VS}$ $6(30 \%)$ respectively; $\mathrm{p}=0.110)$.these agreement with other researches Frass et al. [12], Abdeldayem HM, et al. [24]. Two cases $(10 \%)$ in reverse breech extraction approach group needed blood transfusion intra-operatively, while $10(50 \%)$ were transfused in standard approach group, and the difference between the two groups was statistically significant $(\mathrm{p}=0.0110)$. this is agreement with previous studies $[25,26]$.

The mean fall in HB postoperatively was less in the in reverse breech extraction approach group than in standard approach group (mean11.45 VS mean 9.9 respectively), and the difference between two groups was statistically significant $(p=<0.001)$.this agreement with Frass et al. [12] and Abdeldayem HM, et al. [24]. A shorter mean operative time was reported in reverse breech extraction approach group of this series in comparison to the standard approach group $(33.0 \pm 11.85 \mathrm{~min}$ VS $29.50 \pm 5.83 \mathrm{~min})$, and the difference between two groups was statistically highly significant $(\mathrm{p}=0.243)$.

This match very well with other investigators Frass et al. [12], Abdeldayem HM, et al. [24], Baloch et al. [27], Berhan and Berhan et al. [28], Bastani et al. [29], Veisi et al. [30] and Fasubaa et al. [31]. This study total complication in standard approach group 12 (70\%) than reverse breech extraction approach group 10(50\%) and the difference between two groups was statistically highly significant $(\mathrm{p}=0.525)$. This agreement with previous studies.

This study totals no complication in standard approach group $8(30 \%)$ than reverse breech extraction approach group 10(50\%) and the difference between two groups was statistically highly significant $(p=0.525)$. This agreement with previous studies. In 
this study, pyrexia developed in $1(5 \%)$ case in the reverse breech extraction approach group VS 3cases (15\%) in the standard approach group, and the difference between two groups was statistically highly significant $(\mathrm{p}=0.291)$.This agreement with previous studies [15,24,27,31].

Wound infection occurred in 2 cases (10\%) in the reverse breech extraction approach group VS 10cases (50\%) in than standard approach group, and the difference between two groups was statistically highly significant $(\mathrm{p}=0.005)$. This agreement with previous studies $[15,24,27,31]$. However, in their studies, Frass et al. 2011(12), Berhan and Berhan 2014(28), reported that there no statistically significant differences in incidence of endometritis and wound infection between two groups.

In this study, the mean length of hospital stay was $(3.95 \pm 1.61$ days) in the reverse breech extraction approach group VS (5.40 \pm 2.09 days) in the standard approach group, and the difference between the two groups was statistically highly significant $(\mathrm{p}=0.018)$, which was also reported by Fasubaa et al. [31]. However, Frass et al. [12], reported that there were no significant differences in the length of hospital stay between the two groups.

In apgar score showed in this study reverse breech extraction was statistically significant decrease than the standard group at 1 and 5 minutes. In this study showed apgar score $\leq 7$ at 1 minutes was noted in (mean \pm 9 VS mean \pm 5.5 respectively), and the difference between the two groups was statistically significant $(\mathrm{p}=0.001)$.

Noted in apgar score $\leq 7$ at 5 minutes was (mean \pm 10 VS mean \pm 9 respectively), and the difference between the two groups was statistically significant ( $p=0.003)$.Other parameter of neonatal outcome were better in the reverse breech extraction approach group than in the standard approach group, but the difference between the two groups failed to show statistically significant. This agreement with Abdeldayem HM et al. [24], Fasubaa et al. [31], Berhan and Berhan [28]. In this study noted 1 case fetal injury (hip dislocation) in reverse breech extraction approach group than in the standard approach group.

This agreement with Fasubaa et al. [32], Veisi et al. [30] and Abdeldayem HM, et al. [24]. However, disagree with Frass et al. [12] and Kadham [26], which in both groups no fetal injury. A relatively high transverse uterine incision and gentle grasping wound reduce this complication. In this study revealed postpartum hemorrhage decrease in HB level was more in the standard approach group than the reverse breech extraction approach group and this explained by increase the intra partum hemorrhage among the standard approach group and so increased blood loss which in agreement with Thura et al. [26].

In the study of Kafali et al. [13] the low vertical uterine incision was chosen for the reverse breech extraction rather than the low transverse as it ensured successful grasp of the fetal feet with less trauma to the uterus or fetus. This study concludes that the pulling method (reverse breech extraction) for delivery of impacted fetal head at caesarean section for obstructed labor is safer than the pushing method. This technique should be considered in cases where the fetal legs or pelvis seem to be more accessible and before attempting to disengage the fetal head by pushing it through the vagina. More data are needed to establish the frequency and the extent of obstructed labor and deeply engaged head during caesarean section in our community and to determine the management protocol that carries the lowest risk in such circumstances.

\section{Conclusion}

This study shows that the reverse breech extraction technique for delivery of a deeply impacted fetal head in second-stage caesarean section carries a significantly lower risk of extension of the uterine incision compared with the push method. It is also associated with a lower risk of infection a lower operative time, and less operative blood loss; however, there is no difference in blood transfusion rate and neonatal outcome.

\section{References}

1. Neilson JP, Lavender T, Quenby S, Wray S (2003) Obstructed labour: reducing maternal death and disability during pregnancy. British Medical Bulletin 67(1): 191-204.

2. Dolea C, AbouZahr C (2003) Global burden of obstructed labour in the year 2000 [Internet]. Evidence and Information for Policy (EIP), WHO, Geneva. Global Burden of Disease 2000: 1-17.

3. Chhabra S, Gandhi D, Jaiswal M (2000) Obstructed labour: a preventable entity. J Obstet Gynaecol 20(2): 151-153.

4. Dafallah SE, Ambago J, El-Agib F (2003) Obstructed labor in a teaching hospital in Sudan. Saudi Med J 24(10): 1102-1104.

5. Melah GS, El-Nafaty AU, Massa AA, Audu BM (2003) Obstructed labour: a public health problem in Gombe, Gombe State, Nigeria. J Obstet Gynaecol 23(4): 369-373.

6. Weiner R, Ronsmans C, Dorman E, Jilo H, Muhoro A, et al. (2003) Labour complications remain the most important risk factors for perinatal mortality in rural Kenya. Bull World Health Organ 81(8): 561-566.

7. Adhikari S, Dasgupta M, Sanghamita M (2005) Management of obstructedlabor: a retrospective study. Journal of Obstetrics and Gynecology of India 55: 48-51.

8. Levy R, Chernomoretz T, Appelman Z, Levin D, Or Y, et al. (2005) Head pushing versus reverse breech extraction in cases of impacted fetal head during cesarean section. Eur J Obstet Gynecol Reprod Biol 121(1): 24-26.

9. Van Beekhuizen HJ, Unkels R, Mmuni NS, Kaiser M (2006) Complications of obstructed labour: pressure necrosis of neonatal scalp and vesicovaginal fistula. Lancet 368(9542): 1210.

10. Frass KA, Al Eryani A, Al-Harazi AH (2011) Reverse breech extraction versus head pushing in cesarean section for obstructed labor. A comparative study in Yemen. Saudi Med J 32(12): 1261-1266.

11. Philpott RH (1982) The recognition of cephalopelvic disproportion. Clin Obstet Gynaecol 9(3): 609-624. 
12. Ara A (2004) Outcome of obstructed labor. Journal of Postgraduate Medical Institute 18: 512-517.

13. Kafali $H$ (2002) Cesarean breech extraction for impacted fetal head in deep pelvis after a prolonged obstructed labour: a cesarean technique variation. The Internet Journal of Gynecology and Obstetrics 2(2): 1-4.

14. Blickstein I (2004) Difficult delivery of the impacted fetal head during cesarean section: intraoperative disengagement dystocia. J Perinat Med 32(6): 465-469.

15. Chopra S, Bagga R, Keepanasseril A, Jain V, Kalra J, et al. (2009) Disengagement of the deeply engaged fetal head during cesarean section in advanced labor: conventional method versus reverse breech extraction. Acta Obstetricia Et Gynecologica Scandinavica 88(10) 1163-1166.

16. Barbieri RL (2012) Difficult fetal extraction at cesarean delivery: what should you do? OBG Management 24: 8-12.

17. Nailla Memon senior Registar (2013-2014).

18. Friedman EA (1955) ObstetGyneal.

19. Mahler H (1987) Lancet 1: 668-670.

20. Mccarty MA (2002) brief history of the world health organization? Lancet 360: 1111-1112.

21. Martin JA, Hamilton BE, Sutton PD, Ventura SJ, Menac- ker F, et al (2003) Births: final data for 2002. Natl Vital Stat Rep 52(10): 1-113.

22. Fong YF, Arulkumaran S (1997) Breech extraction- an alternative method of delivering a deeply engaged head at cesarean section. Int ] Gynecol Obstet 56(2): 183-184.

23. Medically Reviewed by Nicole Galan, RN. on (2013)- written by Erizacirino.
24. Nooh AM, Abdeldayem HM, Ben-Affan O (2017) Reverse breech extraction versus the standard approach of pushing the impacted fetal head up through the vagina in caesarean section for obstructed labour: A randomised controlled trial. J Obstet Gynaecol 37(4): 459-463.

25. Bastani P, Pourabolghasem S, Abbasalizadeh F, Motvalli L (2012) Comparison of neonatal and maternal outcomes associated with headpushing and head-pulling methods for impacted fetal head extraction during cesarean delivery. Int J Gynaecol Obstet 118(1): 1-3.

26. Kadhum TJ (2009) Head pushing versus reverse breech extraction for delivery of impacted fetal head during caesarean section. Kufa Medical Journal 121(1): 200-205

27. Baloch S, Khaskheli M, Khushk IA, Sheeba A (2008) Frequency of second stage intervention and its outcome in relation with instrumental vaginal delivery versus Caesarean section. J Ayub Med Coll Abbottabad 20(1): 87-90.

28. Berhan Y, Berhan A (2014) A meta-analysis of reverse breech extraction to deliver a deeply impacted head during cesarean delivery. Int J Gynaecol Obstet 124(2): 99-105.

29. Veisi F, Zangeneh M, Malekkhosravi S, Rezavand N (2012) Com parison of 'push' and 'pull' methods for impacted fetal head extraction during cesarean delivery. Int J Gynaecol Obstet 118(1): 4-6.

30. Fasubaa OB, Ezechi OC, Orji EO, Ogunniyi SO, Akindele ST, et al. (2002) Delivery of the impacted head of the fetus at caesarean section after prolonged obstructed labour: a randomised comparative study of two methods. J Obstet Gynaecol 22(4): 375-378.

31. Fasubaa OB, Ezechi OC, Orji EO, Ogunniyi SO, Akindele ST, et al. (2002) Delivery of the impacted head of the fetus at caesarean section after prolonged obstructed labour: a randomized comparative study of two methods. J Obstet Gynaecol 22(4): 375-378.

\section{Your next submission with Juniper Publishers} will reach you the below assets

- Quality Editorial service

- Swift Peer Review

- Reprints availability

- E-prints Service

- Manuscript Podcast for convenient understanding

- Global attainment for your research

- Manuscript accessibility in different formats ( Pdf, E-pub, Full Tsext, Audio)

- Unceasing customer service

Track the below URL for one-step submission https://juniperpublishers.com/online-submission.php 